$\mathbb{P}$ periodica polytechnica

Chemical Engineering

57/1-2 (2013) 85,91

doi: 10.3311/PPch.2175

http://periodicapolytechnica.org/ch

Creative Commons Attribution (i)

RESEARCH ARTICLE

\section{Comparison of additive and reactive phosphorus-based flame retardants in epoxy resins}

\author{
Beáta Szolnoki / Andrea Toldy / Péter Konrád / Gábor Szebényi / György Marosi
}

Received 2013-03-01, accepted 2013-05-16

\begin{abstract}
The aim of this work was to investigate the effect of phosphorus-based additive and reactive flame retardants (FR) on the flammability and mechanical properties of a pentaerythritol-based model epoxy resin system cured with a cycloaliphatic diamine hardener. Commercially available ammonium polyphosphate (APP) was used as additive and 9,10-dihydro-9-oxa-10-phosphaphenantrene-10-oxide (DOPO) as reactive flame retardant. The behaviour of these systems was also compared to a recently synthesized phosphorus-containing amine (TEDAP), which can be used both as flame retardant and crosslinking agent.
\end{abstract}

\section{Keywords}

additive and reactive flame retardancy $\cdot$ epoxy resin $\cdot D O P O$. ammonium polyphosphate $\cdot$ cone calorimeter

\section{Acknowledgement}

This work is connected to TÁMOP-4.2.1/B-09/1/KMR-20100002 project supported by the New Széchenyi Plan. The research leading to these results has received funding from the European Union's Seventh Framework Programme (FP7/20072013) for the Clean Sky Joint Technology Initiative under grant agreement $N^{\mathrm{o}} 270599$. Andrea Toldy acknowledges the financial support received through János Bolyai Scholarship of the Hungarian Academy of Science.

\section{Beáta Szolnoki}

Department of Organic Chemistry and Technology, Budapest University of Technology and Economics, Budafoki út 8. H-1111 Budapest,, Hungary e-mail: bszolnoki@mail.bme.hu

\section{Andrea Toldy \\ Péter Konrád \\ Gábor Szebényi}

Department of Polymer Engineering, Budapest University of Technology and Economics, Múegyetem rkp.3., Budapest, H-1111, Hungary

\section{György Marosi}

Department of Organic Chemistry and Technology, Budapest University of Technology and Economics, Budafoki út 8. H-1111 Budapest,, Hungary

\section{Introduction}

Epoxy resins are extensively used in various industrial application fields as, for example, adhesives, surface coatings, laminates and matrix materials. Despite their exceptional characteristics like prominent adhesion to many substrates; moisture, solvent and chemical resistance; low shrinkage on cure; outstanding mechanical and electronic resistant properties, their flammability can still limit their application. The heat exchange during polymerization is also influences the potential fields of application [1]. The use of structural units made of composites of high mechanical loading capability, being suitable for replacing metallic structures, is rapidly increasing in the aircraft industry [2]. In the newest large commercial airliners the fuselage, the wings and the empennage are also made of carbon fibre reinforced composites. In case of fire, the health risk is not the only danger; also the decrease of mechanical properties can be significant [3]-[5]. Due to environmental reasons, the use of halogencontaining flame retardants needs to be decreased. Their most promising substitutes are the phosphorus-containing flame retardants owing to their extremely wide and versatile range, since the $\mathrm{P}$ element exists in various oxidation states [6]-[9]. The fire retarded epoxy resins with conventional additives are usually of poorer physical/mechanical properties than the unmodified ones; therefore the use of reactive comonomers is preferred in many cases. A great advantage of the reactive flame retardants is that they are chemically bound to the matrix, so their release to the environment is blocked, thus we can avoid the formation of FR-containing wastewaters [10]. However, incorporating them into the polymer structure several properties of the material generally decrease. The greatest challenge for the current research works is to create a composite system with optimal balance of mechanical performance and flame retardancy.

Ammonium polyphosphate (APP), an additive-type flame retardant, with high phosphorus (31-32 wt\%) and nitrogen (14$15 \mathrm{wt} \%$ ) content, is extensively used in thermoplastic polymers, such as polypropylene [11, 12], ethylene-vinyl-acetate [13], polyurea [14], polylactide [15], etc. The literature deals with the application of APP in aromatic epoxy resins, mainly in diglycidyl ether of bisphenol-A (DGEBA), however 
aliphatic epoxies are only scarcely discussed. In DGEBA/low molecular weight polyamide (LWPA) matrix, the application of $5 \mathrm{wt} \%$ APP resulted in V-0 rating [16]. By the application of microencapsulated ammonium polyphosphate (MFAPP) in DGEBA/cycloaliphatic amine system, $9 \mathrm{wt} \%$ additive was necessary to reach V-0, accompanied with an LOI value of 30 [17]. In a glass fibre reinforced epoxy resin composite, the application of $5 \mathrm{wt} \%$ of APP resulted in a V-0 composition, however the LOI value was only $26 \mathrm{~V} / \mathrm{V} \%$ [18]. In a mixed DGEBADGEBF epoxy, the peak of heat release could be reduced by only $30 \%$ even at $20 \mathrm{wt} \%$ of APP-content [19].

9,10-Dihydro-9-oxa-10-phosphaphenantrene-10-oxide (DOPO) is considered as the most common comonomer which is used as reactive flame retardant. It can be incorporated into the resin structure by reacting it with the oxirane ring of the epoxy component. With increasing amount of the DOPO-modified DGEBA, epoxy resin of 1-3\% phosphorus content has been synthesized [20]. V-0 rating in UL-94 test could be reached when applying $3 \mathrm{wt} \%$ phosphorus in the matrix cured with 4,4'-diaminodiphenylmethane (DDM), while the LOI value increased to $30 \mathrm{~V} / \mathrm{V} \%$ [21].

In this work, we aimed to compare the above-mentioned additive and reactive type flame retardants in a pentaerythritol-based model epoxy resin system at the same levels of phosphoruscontent.

\section{Materials and testing methods}

\subsection{Materials}

The epoxy resin matrix consisted of epoxy component type MR 3016 (tetraglycidyl ether of pentaerythritol, properties: nonmodified, resin-like reactive dilutant, epoxy equivalent: 156170 ; viscosity at $25{ }^{\circ} \mathrm{C}$ : $850-1200 \mathrm{mPa} . \mathrm{s}$; density at $25{ }^{\circ} \mathrm{C}$ : $1.24 \mathrm{~g} / \mathrm{cm}^{3}$ ) applied with MH 3122 curing agent (3,3' -dimethyl4,4'-diamino-dicyclohexyl-methane, properties: amine number: 464-490 mg KOH/g; viscosity at $25^{\circ} \mathrm{C}$ : 80-120 mPa.s; density at $20{ }^{\circ} \mathrm{C}: 0.944 \mathrm{~g} / \mathrm{cm}^{3}$ ), both supplied by Ipox Chemicals Ltd., Hungary. This resin system is ideal for lamination and composite production, according to the specifications of the producer.

Ammonium polyphosphate produced by Nordmann Rassmann (NORD-MIN JLS APP) was used as additive type flame retardant (properties: phosphorus content: $31-32 \%$, nitrogen content: $14-15 \%$, average particle size: $15 \mu \mathrm{m}$ ).

As reactive flame retardant, Struktol Polydis 3710 (DOPO; 9,10-dihydro-9-oxa-10-phosphaphenantrene-10-oxide, properties: MM: $216.17 \mathrm{~g} / \mathrm{mol}, \mathrm{mp}: 116^{\circ} \mathrm{C}$ ), supplied by Struktol $\mathrm{GmbH}$ was used. In order to form a phosphorus-containing epoxy component, DOPO was reacted with the MR 3016 at $160{ }^{\circ} \mathrm{C}$ for 6 hours [20, 22]. As two DOPOs were reacted with one molecule of the tetrafunctional epoxy resin, the epoxy equivalent of the product is the double of the original component.

A phosphorus-containing reactive amine, $\operatorname{TEDAP}\left(N, N^{\prime}, N^{\prime \prime}\right.$ tris(2-aminoethyl)-phosphoric acid triamide, properties: amine number: $510-530 \mathrm{mg} \mathrm{KOH} / \mathrm{g}$; viscosity at $20^{\circ} \mathrm{C}$ : $400 \mathrm{mPa}$ ) synthesized according to previous publication of the authors [23] was applied as flame retardant curing agent.

\subsection{Methods}

\subsubsection{Sample preparation}

Preparation of epoxy resin samples: the epoxy and curing agent amine components were mixed at room temperature in a glass beaker in order to obtain a homogenous mixture. In the case of the APP-containing formulations, the flame retardant powder was thoroughly dispersed in the epoxy component, and then the amine component was added and mixed as mentioned above. The samples were cured at room temperature for 24 hours in a silicon mould of appropriate size, and then postcured at $80^{\circ} \mathrm{C}$ for 4 hours to reach the final mechanical properties.

\subsubsection{Flammability tests}

The fire resistance of the reference and flame retarded systems was characterized by limiting oxygen index measurements (LOI, according to ASTM D-2863). The LOI value expresses the lowest oxygen to nitrogen ratio where the combustion of specimen is still self-supporting.

Standard UL-94 flammability tests (according to ASTM 1356-90 and ANSI//ASTM D-635/77, respectively) were also carried out. UL-94 classification is used to determine ignitability, dripping, and flame spreading rates and burning times of the samples.

Mass Loss type cone calorimeter tests were carried out by an instrument made by FTT Inc. using the ASTM E 906 standard method. Specimens $(100 \mathrm{~mm} \times 100 \mathrm{~mm})$ were exposed to a constant heat flux of $50 \mathrm{~kW} / \mathrm{m}^{2}$ and ignited. Heat release values and mass reduction were continuously recorded during burning.

\subsubsection{Mechanical measurements}

The mechanical characteristics of specimens were determined with instrumented tensile tester type Zwick Z020. In each static mechanical measurement at least 5 specimens were tested.

Comparative static tensile strength measurements were carried out on dumb-bell-shaped specimens according to ISO 527 2. The cross-head speed was set to $5 \mathrm{~mm} / \mathrm{min}$; the distance between the grips was $110 \mathrm{~mm}$.

The flexural strength was determined according to ISO 178:2001, using rectangular specimens of $10 \mathrm{~mm} \times 4 \mathrm{~mm}$ (width $\times$ thickness). The cross-head speed was set to $5 \mathrm{~mm} / \mathrm{min}$; the span was $64 \mathrm{~mm}(16 \times$ thickness $)$.

Dynamic mechanical analysis (DMA) was used for the determination of the glass transition temperature of the reference and flame retarded resins. The measurements were carried out in a DMA Q800 instrument, in the range of $20-150{ }^{\circ} \mathrm{C}$, with a heating rate of $3{ }^{\circ} \mathrm{C} / \mathrm{min}$, applying 3 point bend testing mode of $50 \mathrm{~mm}$ span length with a pre-load force of $0.1 \mathrm{~N}$. $20 \mu \mathrm{m}$ was 
the amplitude of the loading with $1 \mathrm{~Hz}$ frequency. The $\mathrm{T}_{\mathrm{g}}$ was determined at the peak of $\tan (\delta)$.

\section{Results and discussion}

\subsection{Flammability properties}

The flame retardant efficacy of an additive (APP) and two types of reactive flame retardants was compared. The additive flame retardant (FR) was used as received. Commercially available DOPO was reacted with the pentaerythritol-based epoxy component (MR 3016) in order to form phosphorus-containing epoxy component, which can act as reactive flame retardant. As every second epoxy group of the resin was reacted with the flame retardant DOPO, the epoxy equivalent of the synthesized P-containing epoxy component (referred as EP-DOPO in the followings) was doubled, as expected, according to the titration measurements. The synthesized phosphorus-containing amine (TEDAP) can act as reactive flame retardant as it contains primary and secondary amines, which functional groups are able to open the epoxy ring and so cure the resin. The flame retardants compared in this study thus are representing all the possibilities for the flame retardancy of epoxy resins, i.e. both components (epoxy and hardener) can contain P-atoms, and also an additive type material was tested.

APP was applied in 5 different concentrations in the reference epoxy resin system (pentaerythritol-based epoxy component cured with cycloaliphatic hardener) in order to change the phosphorus content by $1 \mathrm{wt} \%$ in the range of $1-5 \%$. In the case of the reactive flame retardants (EP-DOPO and TEDAP), in order to increase the P-content, portions of the epoxy and amine component were replaced by the corresponding flame retarded ones, respectively. By this method, maximum $4 \mathrm{wt} \%$ P-content could be reached when the epoxy component was totally replaced by EP-DOPO, while $3 \mathrm{wt} \%$ of phosphorus could be incorporated to the resin at the outmost when applying TEDAP as crosslinking agent.

\subsubsection{UL-94 and LOI}

The UL-94 test is an industrially accepted way for the classification of flame retardancy of materials (of the same thickness). The LOI (oxygen volume percentage in the surrounding atmosphere) values represent also an easily comprehensible comparison of different materials. As the oxygen content of the air is $21 \mathrm{~V} / \mathrm{V} \%$, the samples which burn continuously when ignited in air, has an LOI value of 21 .

The UL-94 and LOI values of the prepared samples are summarized in Table 1. The numbers in parenthesis after HB classification represent the flame spread rates (when it was measurable).

The reference pentaerythritol-based matrix cured with cycloaliphatic hardener showed an LOI value of $23 \mathrm{~V} / \mathrm{V} \%$ which indicates an easily flammable material. With the addition of the additive-type flame retardant (APP) the LOI value could be increased by $4 \mathrm{~V} / \mathrm{V} \%$ even at $1 \%$ phosphorus-content. At $2 \mathrm{wt} \%$
Tab. 1. LOI and UL-94 values of the samples

\begin{tabular}{lcc}
\hline Flame retardant & $\begin{array}{c}\text { LOI } \\
(\mathrm{V} / \mathrm{V} \%)\end{array}$ & $\begin{array}{c}\text { UL-94 rating } \\
\text { (horizontal flame spreading) }\end{array}$ \\
\hline reference & 23 & $\mathrm{HB}(32 \mathrm{~mm} / \mathrm{min})$ \\
APP_1\%P & 27 & $\mathrm{HB}(-)$ \\
APP_2\%P & 32 & $\mathrm{HB}(-)$ \\
APP_3\%P & 32 & $\mathrm{HB}(-)$ \\
APP_4\%P & 32 & $\mathrm{~V}-1$ \\
APP_5\%P & 32 & $\boldsymbol{V}-\mathbf{0}$ \\
EP-DOPO_1\%P & 23 & $\mathrm{HB}(14.3 \mathrm{~mm} / \mathrm{min})$ \\
EP-DOPO_2\%P & 23 & $\mathrm{HB}(-)$ \\
EP-DOPO_3\%P & 23 & $\mathrm{HB}(-)$ \\
EP-DOPO_4\%P & 24 & $\mathrm{~V}-2$ \\
TEDAP_1\%P & 25 & $\mathrm{~V}-1$ \\
TEDAP_2\%P & 30 & $\boldsymbol{V}-\mathbf{0}$ \\
TEDAP_3\%P & 33 &
\end{tabular}

P the LOI increased to $32 \mathrm{~V} / \mathrm{V} \%$, which value could not be improved further, despite of the increasing P-content. By the application of DOPO-modified epoxy component (EP-DOPO), no change could be detected in the LOI values, only at $4 \mathrm{wt} \% \mathrm{P}$ content a very slight improvement of $1 \mathrm{~V} / \mathrm{V} \%$ could be reached from 23 to 24 . If the phosphorus-containing amine, TEDAP was used as crosslinking agent, the LOI could be increased significantly. With the increasing P-content, the measured values were 25,30 and $33 \mathrm{~V} / \mathrm{V} \%$, respectively.

The UL-94 test also confirmed the flammability of the reference resin by the rapid flame spreading rate of $32 \mathrm{~mm} / \mathrm{min}$, which makes the sample highly burning, and so the rating HB. When the additive APP was applied at $1 \mathrm{wt} \%$ of phosphorus content, the sample passed the horizontal test, which means no flame spreading rate could be determined. The classification of the APP-containing compositions remained $\mathrm{HB}$ even at $3 \mathrm{wt} \%$ P-content, as the flame reached the brace during the vertical test, while the dripping stopped at $2 \mathrm{wt} \%$. V-1 rating was measured when applying $4 \mathrm{wt} \% P$ in the matrix, while the best, V-0 classification could be reached only at $5 \mathrm{wt} \%$ phosphorus-content (15\% APP-content) indicated in bold italic in Table 1 . All the compositions prepared with EP-DOPO reached only HB rating, however, the flame spreading rate decreased at $1 \mathrm{wt} \%$ P-content by more than $50 \%$ of the value measured for the reference resin (from $32 \mathrm{~mm} / \mathrm{min}$ to $14.3 \mathrm{~mm} / \mathrm{min}$ ). When higher P-loadings were applied, no flame spreading was detected during the horizontal test, but in every case, burning droplets ignited the cotton under the sample. When the P-containing amine, TEDAP was applied as curing agent, even at $1 \mathrm{wt} \% \mathrm{P}$-content the sample passed the requirements of $\mathrm{V}-2$ rating. With increasing FR content, the UL-94 ratings improved, and at 3\% P-loading, reached the best, $\mathrm{V}-0$ rating (Table 1 ).

\subsubsection{Cone calorimeter}

Measurements in Cone calorimeter detect the combustion characteristics of the materials. Sudden heat-shock and forced ignition can be applied to simulate the effect of a burning en- 
vironment in a real fire. In the course of the test, the time to ignition (TTI) can be observed, and the heat release values can be calculated from the recorded data. The peak of heat release rate (pHRR) and the total heat released (THR) values are generally used for determining the efficiency of the flame retardants.

The results obtained for the samples with the three differenttype flame retardants with different P-content are summarized in Table 2

Tab. 2. Cone calorimetric result of the samples

\begin{tabular}{lrrrr}
\hline Flame retardant & $\begin{array}{r}\text { TTI } \\
(\mathrm{sec})\end{array}$ & $\begin{array}{r}\text { pHRR } \\
\left(\mathrm{kW} / \mathrm{m}^{2}\right)\end{array}$ & $\begin{array}{r}\text { THR } \\
\left(\mathrm{MJ} / \mathrm{m}^{2}\right)\end{array}$ & $\begin{array}{r}\text { residue } \\
(\%)\end{array}$ \\
\hline reference & 13 & 706.4 & 103.5 & 0 \\
APP_1\%P & 23 & 546.5 & 108.5 & 10.5 \\
APP_2\%P & 25 & 538.8 & 71.5 & 13.8 \\
APP_3\%P & 29 & 420.8 & 82.5 & 13.6 \\
APP_4\%P & 23 & 358.2 & 76.7 & 17.9 \\
APP_5\%P & 28 & 363.6 & 68.2 & 18.0 \\
EP-DOPO_1\%P & 22 & 704.4 & 97.2 & 2.0 \\
EP-DOPO_2\%P & 26 & 760.3 & 102.7 & 7.5 \\
EP-DOPO_3\%P & 10 & 682.0 & 106.0 & 5.6 \\
EP-DOPO_4\%P & 26 & 648.3 & 92.3 & 11.0 \\
TEDAP_1\%P & 22 & 668.2 & 97.5 & 6.6 \\
TEDAP_2\%P & 17 & 243.7 & 59.4 & 26.0 \\
TEDAP_3\%P & 95 & 111.4 & 28.0 & 40.1 \\
\hline
\end{tabular}

The heat release curves of the APP-containing flame retardant formulations are presented in Figure 1 .

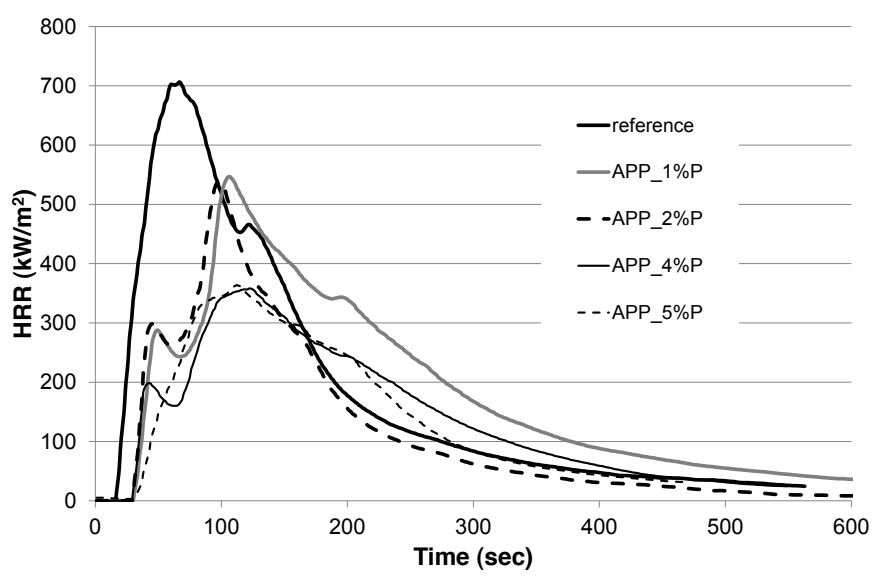

Fig. 1. Heat release curves of APP-containing samples

The time to ignition (TTI) was shifted in all cases, independently of the APP (and so the P) content, to about the double of the TTI recorded for the reference system. The 1 and $2 \% \mathrm{P}$ containing samples show almost the same shape, with a pHRR reduced by $25 \%$. The compositions with $4 \%$ and $5 \% \mathrm{P}$ content acted similarly to each other without any significant difference in their pHRR and THR values. At $5 \mathrm{wt} \%$ P-loading, the THR could be reduced by $30 \%$ compared to the reference resin system, while the residual mass reached $20 \mathrm{wt} \%$.

The compositions prepared with EP-DOPO flame retarded epoxy component (Figure 2) could not decrease the flammabil-



Fig. 2. Heat release curves of EP-DOPO-containing resins

ity of the matrix significantly based on the cone calorimeter test results. The only positive effect, which can be highlighted, is the shift of the peak of heat release in time by about $50 \mathrm{sec}$; however the pHRR values were almost the same in all the cases. The THR values did not change considerably with the increasing phosphorus-content and the increase of the residual mass was also inferior to that of the samples containing APP. DOPO is considered as effective flame retardant for epoxy resins, its inefficacy in the pentaerythritol-based epoxy resin was surprising. Its poor performance can be explained with the incompatibility of the condensed aromatic structured DOPO with the aliphatic epoxy component. This phenomenon highlights the importance of compatibility in the flame retardancy process and the necessity of the adjustment of the structure of the flame retardants to the polymer matrix to be protected.

The application of the P-containing hardener (TEDAP) in increasing amounts led to a continuously decreased flammability of the resin (Figure 3). When only $1 \mathrm{wt} \% \mathrm{P}$ is present in the system, there is no significant difference compared to the reference values, but the higher the P-content, the lower the pHRR and THR values. As for the TEDAP_2\%P, the peak of heat release could be decreased by more than $65 \%$, and also the THR could be reduced by about $40 \%$. When the cycloaliphatic curing agent was totally replaced by the phosphorus-containing one (3 wt\% P), the TTI was shifted in time by $80 \mathrm{sec}$, the pHRR was reduced to the seventh of the original value, and the THR by more than $70 \%$ (Table 2). The amount of the charred residue also increased considerably with the increasing portion of TEDAP: at $2 \mathrm{wt} \% \mathrm{P}$ content $26 \%$, while at $3 \%$ more than $40 \%$ of the original mass remained in the sample holder after combustion (Table 2).

For a better comparison, the HRR curves of the reference sample and matrices containing $3 \mathrm{wt} \% \mathrm{P}$ delivered by differenttype flame retardants, are plotted in Figure 4 In the case of the applied aliphatic matrix there is practically no difference between the reference resin and the DOPO-containing one, which indicates that the DOPO cannot exercise its beneficial effect in this resin system. The samples containing APP and TEDAP reached the same LOI values, but to reach the V-0 rating, the 


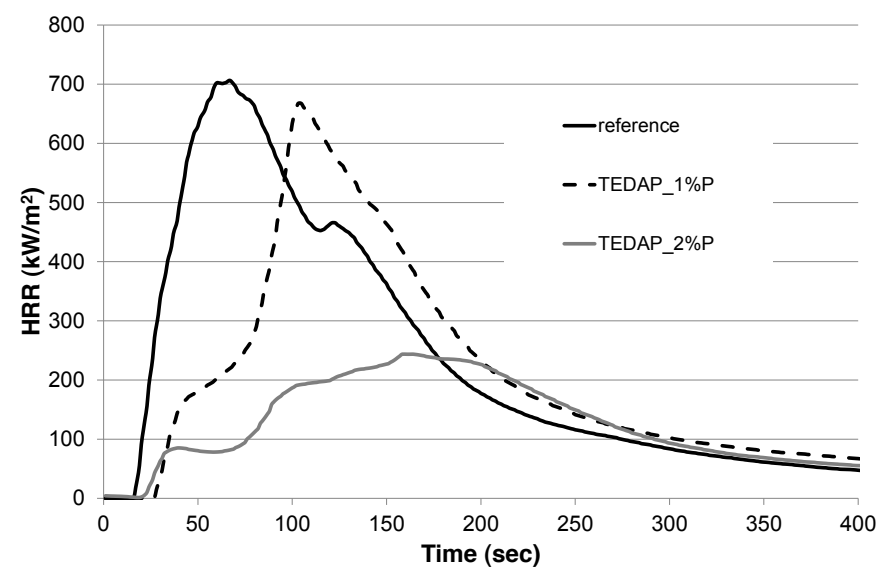

Fig. 3. Heat releases of the TEDAP-cured compositions

application of the latter one was necessary. Concerning their heat release results, the introduction of $3 \% \mathrm{P}$ by means of APP resulted in $40 \%$ decrease of the peak of heat release (pHRR) comparing to the reference epoxy, (to $420 \mathrm{~kW} / \mathrm{m}^{2}$ that of the reference sample was $706 \mathrm{~kW} / \mathrm{m}^{2}$ ), and shifted in time to $150 \mathrm{sec}$, while by the incorporation of the same amount of phosphorus by TEDAP component resulted in $85 \%$ lower pHRR value than that of the reference.

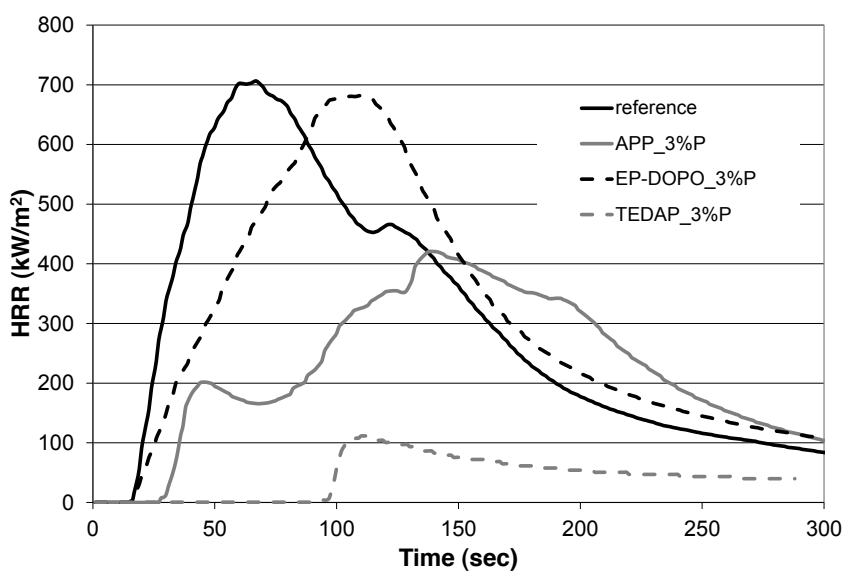

Fig. 4. Comparison of the heat release curves of different flame retardants at $3 \mathrm{wt} \%$ P-content

\subsection{Mechanical characterization}

Although the samples were able to bear the mechanical loadings of fire tests, the EP-DOPO containing formulations showed exceptional brittleness while being mounted in the tensile tester; therefore no mechanical tests could be performed. the results of the samples containing more than $1 \mathrm{wt} \% \mathrm{P}$ could not be evaluated even in the case of DMA measurements.

\subsubsection{Tensile properties}

The samples containing additive flame retardant (APP) show somewhat poorer tensile strength values than the reference resin, but no significant difference could be detected between the FR concentrations applied, which indicate homogenous dispersion of the FR particles (no aggregates could be found in the matrices). When the flame retardant crosslinking agent (TEDAP) is used in low concentration, the tensile strength was as high as that of the reference matrix, however, in higher concentrations, the measured strength was reduced by about $30 \%$. The elasticity moduli of the investigated formulations did not change significantly, only when applying the reactive FR in higher concentrations ( 2 and $3 \mathrm{wt} \%$ ), due to the lower crosslink-density of this system, which could also be proved by DMA measurements (see in Chapter 3.2.3).

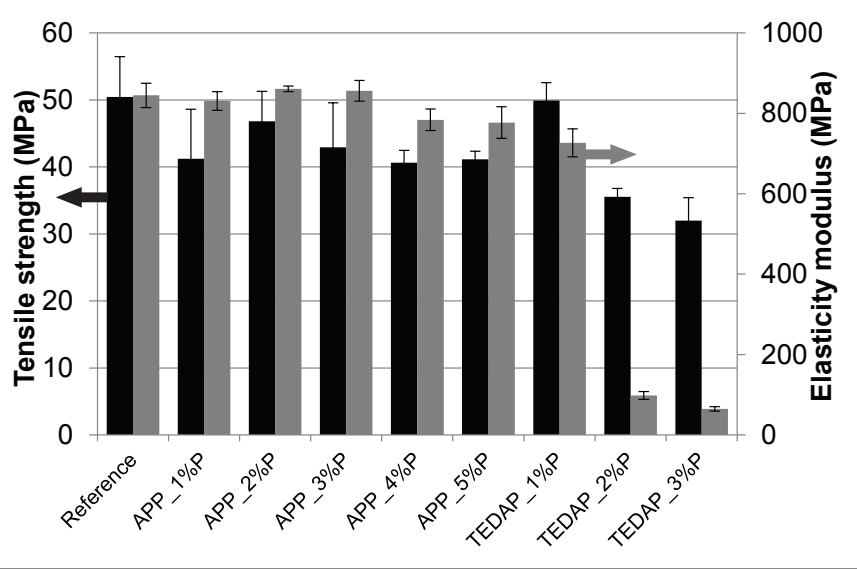

Fig. 5. Tensile strength and elasticity moduli of the flame retarded systems

\subsubsection{Bending properties}

Besides the tensile characterization, three point bending tests were carried out in order to investigate the elasticity of the flame retarded matrices. Based on the measured bending strength and bending elasticity moduli (Figure 6, there is no significant difference between the reference pentaerythritol-based epoxy cured with the cycloaliphatic amine hardener and the flame retarded compositions containing the additive APP. The measured strength values appeared in the range of 70-85 $\mathrm{MPa}$, while the bending elasticity moduli are between $2-2,5 \mathrm{GPa}$. the bending strength decreased significantly, when the reactive fr was used in higher concentrations, especially when the cycloaliphatic amine was fully replaced by the TEDAP; similarly as in the case of the tensile strength measurements. the $3 \mathrm{wt} \%$ P-containing system has $35 \%$ lower strength than that of the reference, while the modulus decreased by tierce.

\subsubsection{Glass transition temperature}

The glass transition temperatures $\left(\mathrm{T}_{\mathrm{g}}\right)$ of the flame retarded matrices were determined at the peak of $\tan (\delta)$ applying 3 point bend testing mode of DMA. The $\mathrm{T}_{\mathrm{g}}$ of the reference resin appeared at $58{ }^{\circ} \mathrm{C}$ (Figure 7). The application of low amount of the additive-type flame retardant (APP) increased this value: when 1 or $2 \mathrm{wt} \%$ phosphorus was incorporated in the matrix (3 and $6 \mathrm{wt} \%$ APP, respectively) the glass transition temperature increased to about $80{ }^{\circ} \mathrm{C}$. When about $10 \mathrm{wt} \%$ APP was present in the system, this value reached even more than $90{ }^{\circ} \mathrm{C}$. This phenomenon can be explained by the presence of the welldispersed FR particles. By means of their homogeneity and rigidity, the APP particles can block the segmental movements 


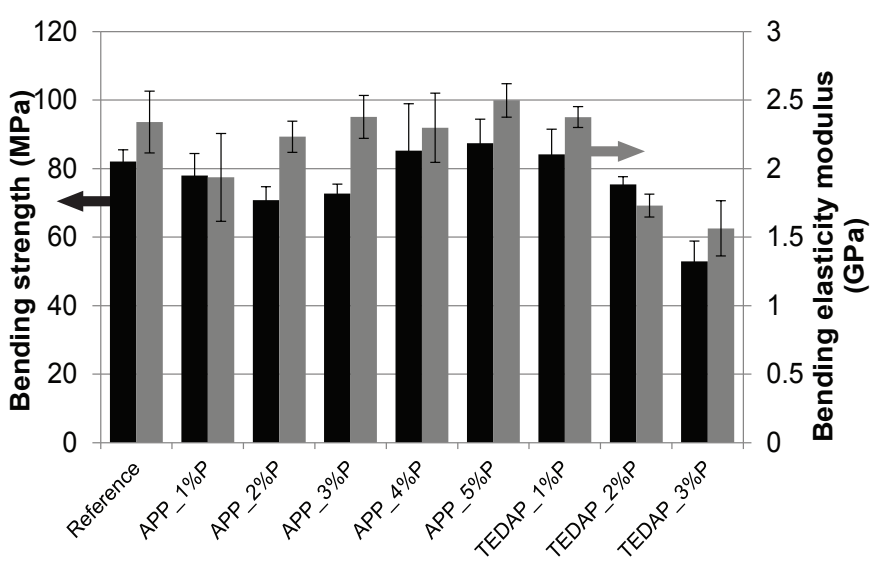

Fig. 6. Bending properties of the flame retardant formulations

of the cross-linked epoxy matrix. When higher concentrations were applied, this beneficial effect was compensated by the interaction of monomers with the filler particles during the polymerization process, which reduces the degree of crosslinking, so the $T_{g}$ decreases comparing to the reference level.

If TEDAP was used as hardener, the chemical structure of the resulted epoxy network was changed. As the reference hardener, due to the cycloaliphatic rings in its structure, is somewhat rigid, consequently higher $T_{g}$ is foreseen for the reference composition than with TEDAP having quite long aliphatic chains. The epoxy resin with TEDAP allows faster segmental movements within the network. The $T_{g}$ results are in good accordance with these expectations: the higher the aliphatic TEDAP-content, the lower the $T_{g}$. When the cycloaliphatic hardener is totally replaced, the glass transition temperature was decreased by $30 \%$, from 58 to $40{ }^{\circ} \mathrm{C}$ (Figure 7).

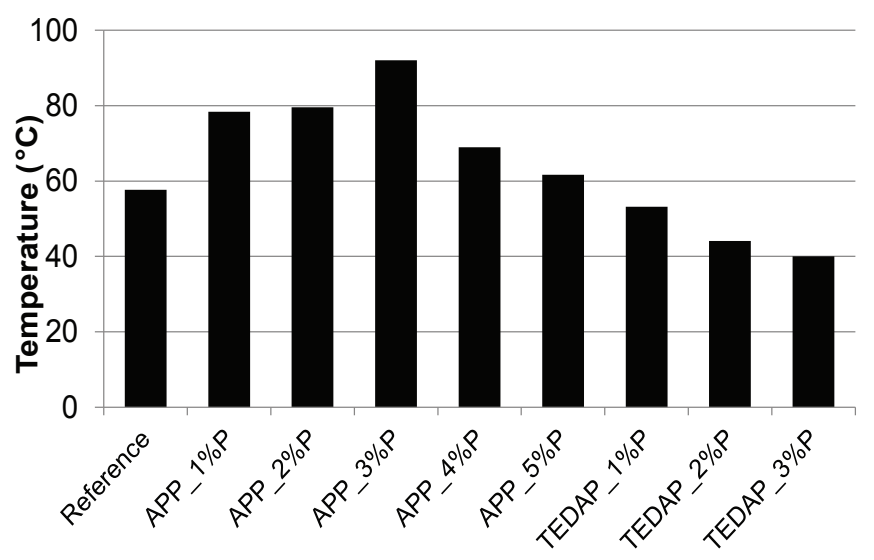

Fig. 7. Glass transition temperatures

\section{Conclusions}

In this work, three types of phosphorus-based flame retardants were investigated in a model aliphatic epoxy resin. The application of DOPO in this system did not lead to significantly increased flame retardancy because of the molecular incompatibility of the components due to the different character of the flame retardant, with condensed aromatic structure, and the aliphatic epoxy component. Still, the flame spreading rate decreased in the UL-94 test, and also the peak of heat release could be shifted in time. The additive APP and the reactive TEDAP decreased the flammability of the resin. To reach V-0 rating, $5 \mathrm{wt} \%$ of phosphorus (15 wt $\%$ APP) was needed in the case of the additive FR, while with the application of TEDAP, $3 \mathrm{wt} \%$ of $\mathrm{P}$ was enough for the same result. The effectiveness of the reactive flame retardant was even more evident in the case of the cone calorimeter tests: the pHRR decreased to its seventh, while the amount of the residual char was $40 \%$. Concerning the mechanical properties, the APP-containing formulations showed somewhat lower tensile strength than the reference resin; however the bending properties were not significantly influenced by the FR additive. The lower crosslink density and thus decreased $T_{g}$ is characteristic to the TEDAP-cured resins, which led to somewhat poorer mechanical properties than those of the reference resin. The requirements of a coating system (flame retardancy and mechanical resistance) can be fulfilled by both systems, however in this pentaerythritol-based epoxy resin the reactive TEDAP proved to be more effective flame retardant than the additive APP.

\section{References}

1 Bárkányi A, Lakatos BG, Németh S, Modelling of heat exchange between drops in suspension polymerization of vinyl chloride, Periodica Polytechnica Chemical Engineering, 56(2), (2012), 55-64, DOI 10.3311/pp.ch.2012-2.02.

2 Marsh G, Airbus A350 XWB update, Reinforced Plastics, 54(6), (2010), 20 24, DOI 10.1016/S0034-3617(10)70212-5.

3 Kandola BK, Horrocks AR, Myler P, Blair D, Mechanical performance of heat/fire damaged novel flame retardant glass-reinforced epoxy composites, Composites Part A: Applied Science and Manufacturing, 34(9), (2003), 863 873, DOI 10.1016/S1359-835X(03)00156-8.

4 Mouritz AP, Mathys Z, Gardiner CP, Thermomechanical modelling the fire properties of fibre - polymer composites, Composites Part B: Engineering, 35(6-8), (2004), 467-474, DOI 10.1016/j.compositesb.2003.09.005.

5 Mouritz AP, Feih S, Kandare E, Mathys Z., Gibson AG, Des Jardin PE, Case SW, Lattimer BY, Review of fire structural modelling of polymer composites, Composites Part A: Applied Science and Manufacturing, 40(12), (2009), 1800-1814, DOI 10.1016/j.compositesa.2009.09.001.

6 Lu SY, Hamerton I, Review of fire structural modelling of polymer composites, Recent developments in the chemistry of halogen-free flame retardant polymers, 27(8), (2002), 1661-1712, DOI 10.1016/S0079-6700(02)00018-7.

7 Shieh J-Y, Wang CS, Synthesis of novel flame retardant epoxy hardeners and properties of cured products, Polymer, 42(18), (2001), 7617-7625, DOI 10.1016/S0032-3861(01)00257-9.

8 Braun U, Balabanovich Al, Schartel B, Knoll U, Artner J, Ciesielski M, Döring M, Perez R, Sandler JKW, Altstädt V., Hoffmann T, Pospiech $\mathbf{D}$, Influence of the oxidation state of phosphorous on the decomposition and fire behaviour of flame-retarded epoxy resin composites, Polymer, 47(26), (2006), 8495-8508, DOI 10.1016/j.polymer.2006.10.022.

9 Hergenrother PM, Thompson CM, Smith Jr. JG, Connell JW, Hinkley JA, Lyon RE, Moulton R, Flame retardant aircraft epoxy resins containing phosphorous, Polymer, 46(14), (2005), 5012-5024, DOI 10.1016/j.polymer.2005.04.025.

10 Hosseini AM, Tungler A, Horváth EZ, Shay Z, Széles É, Catalityc wet oxidation of real process wastewaters, Periodica Polytechnica Chemical Engineering, 55(2), (2011), 49-57, DOI 10.1016/j.polymer.2005.04.025.

11 Lin H, Yan H, Liu B, Wei L, Xu B, The influence of KH-550 on properties of ammonium polyphosphate and polypropylene flame retardant com- 
posites, Polymer Degradation and Stability, 96(7), (2011), 1382-1388, DOI 10.1016/j.polymdegradstab.2011.03.016.

12 Bocz K, Bárány T, Toldy A, Bodzay B, Csontos I, Madi K, Marosi G, Self-extinguishing polypropylene with a mass fraction of $9 \%$ intumescent additive - A new physical way for enhancing the fire retardant efficiency, Polymer Degradation and Stability, 98(1), (2013), 79-86, DOI 10.1016/j.polymdegradstab.2012.10.029.

13 Riva A, Camino G, Fomperie C, Amigouët P., Fire retardant mechanism in intumescent ethylene vinyl acetate compositions, Polymer Degradation and Stability, 82(2), (2003), 341-346, DOI 10.1016/S0141-3910(03)00191-5.

14 Mariappan T, Wilkie CA, Thermal and fire retardant properties of polyuria, Polymery, 58, (2013), 371-384.

15 Ke C-H, Li J, Fang K-Y, Zhu Q-L, Zhu J, Yan Q, Wang Y-Z, Synergistic effect between a novel hyperbranched charring agent and ammonium polyphosphate on the flame retardant and anti-dripping properties of polylactide, Polymer Degradation and Stability, 95(5), (2010), 763-770, DOI 10.1016/j.polymdegradstab.2010.02.011.

16 Wang Y-S, Liu Y, Zhao H-B, Liu J, Wang D-Y, Song Y-P, Wang Y$\mathbf{Z}$, Metal compound-enhanced flame retardancy of intumescent epoxy resins containing ammonium polyphosphate, Polymer Degradation and Stability, 94(4), (2009), 625-631, DOI 10.1016/j.polymdegradstab.2009.01.006.

17 Wu K, Zhang Y-K, Zhang K, Shen M-M, Hu Y, Effect of microencapsulation on thermal properties and flammability performance of epoxy composite, Journal of Analytical and Applied Pyrolysis, 94, (2012), 196-201, DOI 10.1016/j.jaap.2011.12.009.

18 Patrick Lim WK, Mariatti M, Chow WS, Mar KT, Hu Y, Effect of intumescent ammonium polyphosphate (APP) and melamine cyanurate $(M C)$ on the properties of epoxy/glass fiber composites, Composites Part B: Engineering, 43(2), (2012), 124-128, DOI 10.1016/j.compositesb.2011.11.013.

19 Suihkonen R, Nevalainen K, Vuorinen J, The effect of ammonium polyphosphate and nanoclay on the rheological, thermal and flame retardant properties of epoxy, Annual Transactions of the Nordic Rheology Society, 17, (2009), 263-268.

20 Wang CS, Lin $\mathbf{C H}$, Synthesis and properties of phosphorus-containing epoxy resins by novel method, Journal of Polymer Science: Part A: Polymer Chemistry, 37(21), (1999), 3903-3909, DOI 10.1002/(SICI)10990518(19991101)37:21<3903::AID-POLA4>3.0.CO;2-X.

21 Schäfer A, Seibold S, Walter O, Döring M., Novel high $T_{\mathrm{g}}$ flame retardancy approach for epoxy resins, Polymer Degradation and Stability, 93(2), (2008), 557-560, DOI 10.1016/j.polymdegradstab.2007.11.016.

22 Lin CH, Wang CS, Novel phosphorus-containing epoxy resins Part 1. Synthesis and properties, Polymer, 42(5), (2001), 1869-1878, DOI 10.1016/S0032-3861(00)00447-X.

23 Toldy A, Anna P, Csontos I, Szabó A, Marosi G, Intrinsically flame retardant epoxy resin - fire performance and background - Part 1., Polymer Degradation and Stability, 92(12), (2007), 2223-2230, DOI 10.1016/j.polymdegradstab.2007.04.017. 